\title{
Transient elastography for liver fibrosis in children with chronic liver disease
}

*Yogesh Waikar ${ }^{1}$

Sri Lanka Journal of Child Health, 2021; 50(2): 294-298
The returning wave's velocity is converted into liver stiffness measurement (LSM). LSM is expressed in Kpa. TE uses $\mathrm{E}=3 \mathrm{pVs}^{2}$, based on Hooke's formula where E=Young's modulus; $\mathrm{P}=$ mass density; $\mathrm{Vs}=$ velocity of shear wave ${ }^{1,2}$. TE calculates LSM in a specific cylindrical measured tissue volume in the area of interest depending upon the probe ${ }^{1,2}$. Three probes are available; S1, S2 and M. LSM is the measure of liver fibrosis ${ }^{3}$. Liver steatosis is measured by a different noninvasive modality in terms of controlled attenuation parameter $^{3}$. I did not calculate the controlled attenuation parameter values in my series.

\section{Method}

I retrospectively studied 41 patients with CLD. Twenty boys and 21 girls were included. The most common cause of underlying CLD was neonatal cholestasis which was about $24 \%(n=10)$ in my series. Neonatal cholestasis syndrome included biliary atresia, neonatal hepatitis and paucity of bile ducts. Liver biopsy data were available in 11 of 41 patients. The stage of fibrosis in the histopathology report was noted. Upper GI endoscopy report, where available, was analysed. Endoscopy was done in almost all patients after informed consent to note presence or absence of varices. Median liver stiffness was calculated in all patients with the help of the Fibroscan Machine@402 model Echosense Europe. All manufacture recommendations were followed.

TE was performed by a single experienced technician. All children were kept fasting for 3 hours prior to the procedure. No sedation was used. For very young children, to reduce agitation and crying, sucrose dipped gauze for non-nutritive sucking was used. None of the patients had ascites. TE was done in a dorsal decubitus position with the right arm in maximum abduction using the right lobe of the liver in intercostal space. Only M probe was used. Ten shots within 5 minutes were taken. The median liver stiffness measured by shots was calculated as LSM in K pa. As an indicator of variability $I Q R$ i.e. ratio of inter-quartile range of liver stiffness to median value (IQR/M) was calculated. IQR/M $>0.3$ readings were discarded. Fibroscan values were taken at 4 different points in each case i.e. highest possible inter-costal space in anterior axillary line, highest possible inter costal 
space in mid-clavicular line and one intercostal space below /above the mentioned positions.

Three probes, S1 probe for chest circumference $<45 \mathrm{~cm}, \mathrm{~S} 2$ probe for $45-75 \mathrm{~cm}$ and $\mathrm{M}$ probe for $>75 \mathrm{~cm}$ chest circumference were recommended by the manufacturer. I used $\mathrm{M}$ probe in all the cases. Few studies ${ }^{4}$ noted no difference in LSM value between $S$ and $M$ probe. Fibroscan $S$ probe $(5$ $\mathrm{MHz}$; diameter $5 \mathrm{~cm})^{4}$ is better in children $<2$ years and XL probe $(2.5 \mathrm{MHz} \text {; diameter } 10 \mathrm{~mm})^{5}$ in children with very thick adipose tissue but in my centre they were not available. In all 41 children LSM could be calculated with nil failure rates. Youngest patient we did was 6 months of age. Oldest child was 16 years of age.

Ethical issues: As it was a retrospective study, no ethical clearance was obtained and informed consent was not feasible. The study was carried out in my own clinic on an outpatient basis. This is a private set up, not attached to any institution and hence confidentiality of data is secure.

\section{Results}

The most common cause of underlying CLD was follow up patients of neonatal cholestasis syndrome viz. 10. There was a case of chronic hepatitis B and hepatitis C. Autoimmune hepatitis constituted about $12 \%$ of total studied cases. Out of 41 only 4 cases were of metabolic liver disease. Wilson's disease was not included in this subgroup. Total number of Wilson disease patients was 8. They were analysed separately. I could not find the cause of chronic hepatitis in 8 patients, labelling them as cryptogenic chronic hepatitis. I could do liver biopsy in 11 patients of the total cohort of 41 . Stage 3 liver fibrosis was noted in 5 cases. The remaining 6 patients had stage 2 liver fibrosis.

Nineteen (46\%) children scanned with fibroscan had median liver stiffness measurement $>10 \mathrm{kpa}$. The remaining 22 of 41 had LSM $<10 \mathrm{Kpa}$. Forty nine percent had splenomegaly. Five children in the series had gastro-oesophageal varices. None of children with CLD had portal hypertensive gastropathy or isolated gastric varices.

About $80 \%$ of patients who had stage 3 fibrosis on liver biopsy had median liver stiffness of $>10 \mathrm{kpa}$ with sensitivity of $80 \%$ and specificity of $83 \%$, negative predictive value of $83.3 \%$ and specificity of $83 \%$. Using Chi-square statistics with Yate's correction (Fisher exact) $\mathrm{p}$ value was 0.135 so that the association was not statistically significant as depicted in table 1. Small sample size may be the cause.

Table 1: Liver fibrosis stage on histopathology - Liver stiffness measurement on fibroscan

\begin{tabular}{|c|c|c|c|}
\hline Stage of liver Fibrosis & LSM $\leq \mathbf{1 0}$ & LSM>10 & Total \\
\hline 2 & 5 & 1 & 6 \\
\hline 3 & 1 & 4 & 5 \\
\hline Grand total & 6 & 5 & 11 \\
\hline
\end{tabular}

Twice the number of patients who had splenomegaly on clinical examination had median liver stiffness $>10 \mathrm{~K}$ pa $(\mathrm{n}=14)$ as compared to patients with splenomegaly but without liver stiffness of $>10 \mathrm{~K}$ pa $(\mathrm{n}=7)$. Splenomegaly in patients with chronic liver disease was an important variable to predict increased median liver stiffness. This correlation was statistically significant $(p=$
0.0182, with Chi-square statistic with Yate's correction (Fisher exact) significant $\mathrm{p}<0.05$; sensitivity $66.67 \%$; specificity $75 \%$, negative predictive value $68.18 \%$; positive predictive value of $73.68 \%$ as depicted in Table 2. I could not establish statistically significant relationship or dependency between presence of varices and median liver stiffness $>10 \mathrm{kpa}$.

Table 2: Clinical splenomegaly and liver stiffness measurement correlation

\begin{tabular}{|l|c|c|c|l|}
\hline \multicolumn{1}{|c|}{ Clinical criteria } & LSM $\leq \mathbf{1 0}$ & LSM $>\mathbf{1 0}$ & Grand total & \multicolumn{1}{c|}{ Comments } \\
\hline No splenomegaly & 15 & 5 & 20 & Positive predictive value $=73.7 \%$ \\
\hline Splenomegaly & 7 & 14 & 21 & Negative predictive value $=68.2 \%$ \\
\hline Grand total & 22 & 19 & 41 & Sensitivity $=66.7 \%$ Specificity $=75 \%$ \\
\hline
\end{tabular}

I did calculate the average median LSM or A(LSM) for specific diseases. A(LSM) for autoimmune hepatitis was $16.28 \mathrm{Kpa}$. Neonatal cholestasis syndrome had A(LSM) of $16.08 \mathrm{Kpa}$. For nonsyndromic paucity of bile ducts we noted A(LSM) OF $17.65 \mathrm{Kpa}$. In Wilson disease A(LSM) was $14.11 \mathrm{Kpa}$. Chronic hepatitis $\mathrm{B}$ and chronic hepatitis $\mathrm{C}$ had $\mathrm{A}(\mathrm{LSM})$ of $4.2 \mathrm{Kpa}$ and $8.4 \mathrm{Kpa}$. Cryptogenic chronic hepatitis had A(LSM) of $12.71 \mathrm{Kpa}$. Duration of chronicity in each case was different.

\section{Discussion}

Importance of non-invasive assessment of liver fibrosis in children is the need of the hour. Serological and radiological tests are options available. Ultrasound based fibroscan, using 
principle of TE to assess liver fibrosis in children, is now easily available.

Proposed normal value of LSM in Indian children is $4.9 \mathrm{Kpa}^{6}$. The mean LSM in healthy non obese individual is $4.68 \mathrm{Kpa}^{7}$. In a few studies age and sex variations were noted. Adolescent boys may have higher TE value compared to adolescent girls ${ }^{6}$. Median LSM increases with age. For 1 to 5 years LSM values are: $3.4 \mathrm{Kpa}$; 6 to 11 years: $3.8 \mathrm{Kpa} ; 12$ to 18 years: $4 \mathrm{Kpa}^{8}$. LSM values are higher in obese group ${ }^{9}$. Childhood obesity is associated with increased hepatic fat deposition which correlates with increased LSM value in subgroup ${ }^{4}$. Sedative drugs or anaesthesia significantly increases liver stiffness in children ${ }^{8}$. One needs to understand these parameters while analysing LSM values. This may lead to miscalculation. Post-prandial status affects liver stiffness measurement ${ }^{9,10}$. It is preferable to be in fasting state prior measuring LSM. Children with poor inter costal space distance; food intake and agitated state (excessive crying with motion-artefacts) may give us wrong LSM values. The largest possible probe should be used to avoid overestimation of fibrosis.

LSM $>10.6 \mathrm{Kpa}$ is associated with significant fibrosis on histopathology ${ }^{4}$ LSM $>15.05 \mathrm{Kpa}$ is correlated with severe fibrosis with good sensitivity and specificity in study by Jain, et $a l^{6}$. De Ledinghen $\mathrm{V}$, et $a l^{11}$ proposed $10.2 \mathrm{Kpa}$ as cut off for significant fibrosis. Fitz Patrick, et al ${ }^{12}$ showed $6.9 \mathrm{Kpa}$ for significant and LSM value more than $7.5 \mathrm{Kpa}$ for severe fibrosis. Nobili, et $a l^{13}$ showed $\mathrm{LSM}>7.4 \mathrm{Kpa}$ and $\mathrm{LSM}>10.2 \mathrm{~K}$ a to be associated with significant and severe fibrosis respectively. The variation in cut off value in different studies is possibly due to heterogeneity in underlying cause and severity. LSM $>15.15 \mathrm{Kpa}$ is helpful to differentiate cirrhotic from non-cirrhotic patients with sensitivity of $85 \%$ and specificity of $91 \%$ in specific biliary atresia cohort ${ }^{14}$. In our case series, we noted $>10 \mathrm{Kpa}$ was associated with stage 3 fibrosis. Specific sub cohort analysis of LSM values for example in biliary atresia, hepatitis B, hepatitis C, NASH, auto immune hepatitis etc. may refine the value of LSM for cut off discrimination in future studies.

In published Indian study ${ }^{6}$ median liver stiffness measurement of more than $10.6 \mathrm{Kpa}$ was associated with significant fibrosis while some studies in children $^{12,13}$ suggested different cut off $>7.4 \mathrm{Kpa}$ or $6.9 \mathrm{Kpa}$. My case series noted median liver stiffness of more than 10Kpa cut off for stage 3 liver fibrosis but this association was not statistically significant. Poor sample size might be the overruling parameter. Variation in cut off value in different studies was due to heterogeneity in underlying aetiology of chronic liver disease and duration.

I did study the aetiological variation in median liver stiffness value. Average median lived stiffness for neonatal cholestasis related chronic liver disease was $16.08 \mathrm{kpa}$, similarly for autoimmune hepatitis, Wilson's disease, cryptogenic chronic liver disease; average median liver stiffness were $16.3 \mathrm{kpa}, \quad 14.1 \mathrm{kpa}, \quad 12.7 \mathrm{kpa}$ respectively. These values were considerably higher than our proposed cut off value 10Kpa. Thus disease specific and duration optimised median liver stiffness cut off should be considered in future studies. Even specific genetic mutations; where possible need to be studied and should be correlated with liver fibrosis on histopathology and fibroscan.

Variceal bleeding is a known complication of portal hypertension in childhood CLD. $31.5 \mathrm{Kpa}$ cut off value in biliary atresia patients to differentiate bleeding group and non-bleeding group was proposed in children with chronic liver disease $\mathrm{e}^{15}$. My case series could not establish a statistically significant relationship between median liver stiffness and presence or absence of gastrooesophageal varices. None of my children had variceal bleeding. Hence I could not differentiate the bleeding and non-bleeding groups.

Splenomegaly in CLD can be due to aetiology itself or complication of chronic liver disease i.e. portal hypertension. I did not measures splenic-stiffness. Earlier study ${ }^{16}$ concluded that variceal bleeding did not occur with splenic stiffness measures $<60 \mathrm{Kpa}$. I did not study splenic stiffness. Clinically palpable spleen in chronic liver disease was associated with increased median liver stiffness in my case series. ( $\mathrm{p}=0.018, \mathrm{p}<0.05$ ). This association was statistically significant. I propose non-invasive fibro-scan to assess liver fibrosis in all patients with chronic liver disease who have splenomegaly.

Main limitation of my case series was limited number of patients in whom we could do liver biopsies. That could be the reason that I could not establish a statistically significant relationship between stage of liver fibrosis and median liver stiffness. The proposed cut off of LSM $>10 \mathrm{Kpa}$ was noted to be associated with stage 3 fibrosis on liver biopsy. Another limitation; I did not have follow up liver stiffness measurement values in our series after specified duration. Hence progression of liver fibrosis with time and it's correlation with prior results could not be done.

Disease and duration specific median liver stiffness charts are needed to avoid heterogeneous cut off values in future. Chronic liver disease with 
splenomegaly should be considered as the valid indication for doing transient elastography to assess liver fibrosis in children.

\section{Conclusions}

Fibroscan can be used as a non-invasive radiological method to assess liver fibrosis in children.

\section{References}

1. De Ledinghen V, Vergniol J. Transient elastography (fibroscan). Gastroentérologie Clinique et Biologique 2008; 32(6 supp 11): 58-67. https://doi.org/10.1016/S03998320(08)73994-0

2. Mueller S, Sandrin L. Liver stiffness: a novel parameter for the diagnosis of liver disease. Hepatic Medicine 2010; 2:49-67. https://doi.org/10.2147/HMER.S7394 PMid: 24367208 PMCid: PMC3846375

3. Sandrin L, Fourquet B, Hasquenoph J-M, Yon S, Fournier C, Mal F, et al. Transient elastography: a new noninvasive method for assessment of hepatic fibrosis. Ultrasound in Medicine and Biology 2003; 29(12):1705-13.

https://doi.org/10.1016/j.ultrasmedbio.200 3.07.001

PMid: 14698338

4. Cho Y, Tokuhara D, Morikawa H, Kuwae Y, Hayashi E, Hirose M, et al. Transient elastography-based liver profiles in a hospital-based paediatric population in Japan. PLoS One 2015; 10(9):e0137239. https://doi.org/10.1371/journal.pone.0137 239

PMid: 26398109 PMCid: PMC4580651

5. Kwon YD, Ko KO, Lim JW, Cheon EJ, Song YH, Yoon JM. Usefulness of transient elastography for non-invasive diagnosis of liver fibrosis in paediatric non-alcoholic steatohepatitis. Journal of Korean Medical Sciences 2019; 34(23): 165.

https://doi.org/10.3346/jkms.2019.34.e165 PMid: 31197983 PMCid: PMC6565925

6. Jain V, Poddar U, Negi TS, Saraswat VA, Krishnani N, Yachcha SK, et al. Utility and accuracy of transient elastography in determining liver fibrosis: a case-control study. European Journal of Pediatrics 2020; 179: 671-7. https://doi.org/10.1007/s00431-019-

03561-y

PMid: 31960149

7. Bazerbachi F, Haffar S, Wang Z, Cabezas J, Arias-Loste MT, Crespo J, et al. Range of normal liver stiffness and factors associated with increased stiffness measurements in apparently healthy individuals. Clinical Gastroenterology and Hepatology 2019; 17(1):54-64.

https://doi.org/10.1016/j.cgh.2018.08.069 PMid: 30196155

8. Tokuhara D, Cho Y, Shintaku H. Transient elastography-based liver stiffness age-dependently increases in children. PLoS One 2016; 11(11): e0166683.

https://doi.org/10.1371/journal.pone.0166 683

PMid: 27861607 PMCid: PMC5115769

9. Goldschmidt I, Streckenbach C, Dingemann C, Pfister ED, di Nanni A, Zapf A, et al. Application and limitations of transient liver elastography in children. Journal of Pediatric Gastroenterology and Nutrition 2013; 57(1): 109-13. https://doi.org/10.1097/MPG.0b013e3182 9206a0

PMid: 23539048

10. DauZat M, Lafortune M, Pat Riglin H, et al. Meal induced changes in hepatic and splanchnic circulation: a noninvasive Doppler study in normal humans. European Journal of Applied Physiology 1994; 68:373-8.

https://doi.org/10.1007/BF00843732

PMid: 8076615

11. de Lédinghen V, Le Bail B, Rebouissoux L, Fournier C, Foucher J, Miette V, et al. Liver stiffness measurement in children using fibroscan: Feasibility study and comparison with fibrotest, aspartate transaminase to platelets ratio index, and liver biopsy. Journal of Pediatric Gastroenterology and Nutrition 2007; 45(4): 443-50.

https://doi.org/10.1097/MPG.0b013e3181 2e56ff

PMid: 18030211

12. Fitzpatrick E, Quaglia A, Vimalesvaran S, Basso MS, Dhawan A. Transient elastography is a useful non-invasive tool for the evaluation of fibrosis in paediatric 
chronic liver disease. Journal of Pediatric Gastroenterology and Nutrition 2013; 56(1): 72-6.

https://doi.org/10.1097/MPG.0b013e3182 6f2760

PMid: 22922372

13. Nobili V, Vizzutti F, Arena U, Abraldes JG, Marra, F, Pietrobattista A, et al. Accuracy and reproducibility of transient elastography for the diagnosis of fibrosis in paediatric non-alcoholic steatohepatitis. Hepatology 2008; 48: 442-8. https://doi.org/10.1002/hep.22376

PMid: 18563842

14. Shen QL, Chen YJ, Wang ZM, et al. Assessment of liver fibrosis by Fibroscan as compared to liver biopsy in biliary atresia. World Journal Gastroenterology 2015; 21(22):6931-6. https://doi.org/10.3748/wjg.v21.i22.6931 PMid: 26078570 PMCid: PMC4462734

15. Sohn H, Park S, Kang Y, Hong Koh, Han SJ, Kim S. () Predicting variceal bleeding in patients with biliary atresia. Scandinavian Journal of Gastroenterology 2019; 54(11): 1385-90. https://doi.org/10.1080/00365521.2019.16 83225

PMid: 31646915

16. Goldschmidt I, Brauch C, Poynard T, Baumann U. Spleen stiffness measurement by transient elastography to diagnose portal hypertension in children, Journal of Pediatric Gastroenterology and Nutrition 2014; 59(2): 197-203. https://doi.org/10.1097/MPG.0000000000 000400

PMid: 24732027 